\title{
Beden Eğitimi ve Spor Yüksekokulunda Okuyan Öğrencilerinin Bazı Değişkenler Açısından Sosyal Beceri Düzeylerinin İncelenmesi
}

\author{
Selahattin AKPINAR* \\ Öznur AKPINAR* \\ Kazım NAS* \\ Veysel TEMEL* \\ Sefa Şahan BİROL* \\ * Karamanoğlu Mehmetbey Üniversitesi, Beden Eğitimi ve Spor Yüksekokulu, KARAMAN
}

\begin{abstract}
Özet
Bu çalıșma Beden Eğitimi ve Spor Yüksek Okulunda okuyan öğrencilerin sosyal beceri düzeylerini inceleyerek, demografik özelliklerine göre farklılaşıp farklılaşmadığını ortaya koymak amacıyla yapılmışıtır. Araşıırmanın örneklemini, 2014-2015 eğitim-öğretim yılı bahar döneminde Karamanoğlu Mehmetbey Üniversitesi, Beden Eğitimi ve spor Yüksekokulunda okuyan 208 öğrenci olușturmaktadır. Araştırmada 1986 yılında Riggio tarafindan geliştirilen Yüksek tarafından 1997 yılında Türkçeye uyarlanan “ Sosyal Beceri Envanteri” uygulanmıştır. Envanterde 90 maddeden oluşan 1-5 arası puanlanan likert tipi bir ölçektir. Araştırma sonucunda Beden Eğitimi ve Spor Yüksekokulunda okuyan öğrencilerin orta seviyede $(\bar{X}=287,12)$ sosyal beceri düzeylerine sahip oldukları tespit edilmiştir. Öğrencilerin cinsiyet, yaş, okuduğu bölüm, kaldığı yer, kredi alıp almama, aylık gelir durumu, babalarının mesleği, annelerinin çalışıp çalışmamaları ve spora ilgi düzeyleri değişkenlerine göre istatistiksel olarak anlamlı bir fark bulunamazken, okuduğu sınıf, annelerinin eğitim durumu, babalarının eğitim durumu, kardeş sayıları ve yaşamlarının büyük bir bölümünü geçirdikleri yerleşim merkezi değişkenlerine göre ise de istatistiksel olarak anlamlı bir fark bulunmuștur.
\end{abstract}

Anahtar Kelimeler: Sosyal Beceri, Üniversite, beden Eğitimi ve Spor,

\section{Investigation of Students' Social Skill Levels Studying in Physical Education and Sports High School in Terms of Some of The Variables}

\begin{abstract}
This study was conducted to determine whether it differs according to demographic characteristics by investigating of students' social skill levels studying in physical education and sports high school according to demographic characteristics. The sample of the study constitutes 208 students studying in the School of Physical Education and Sports high school, Karamanoğlu Mehmetbey University in spring term during the 2014-2015 academic year. "Social Skill Inventory" developed by Riggio in 1986, adapted into Turkish in 1997 by Yüksek in the research was applied. The inventory consists of 90 items scored 1-5 Likert-type scale. At the end of the research, it was found that students studying in Physical Education and Sports School have mid-level (=287.12) on social skills. While statistically significant difference was not found according to students' gender, age, the department of studying, place of residence, whether or not students take credit, income level, their fathers' occupation, whether or not their mothers work and interesting in sports of them, statistically significant difference was found according to studying at department, education level of parents, the number of siblings and spending and the place where they have spent their lives the most.
\end{abstract}

Keywords: Social Skills, University, Physical Education and Sports

\section{GIRIŞ}

Günümüzde insanların fiziksel, duygusal ve toplumsal bakımdan gelişimini, grup çalışmasının kolaylaştırılması, karşılıklı dayanışmanın sağlanması ve toplum üyelerinin kazanılmasının en kolay yollarından biri spor olgusudur(Gode ve Alkan 1998).Bunların yanı sira spor, anlayış ve sorumluluk taşıyabilme ve işbirliği içerisinde düzen sağlama kabiliyetini de geliştirmektedir. Sebatlı ve enerjik olmayı sağlaması, sosyal gruba ve topluma mensubiyet gücünü kazandırmakla, birey ve toplum ilişkilerini daha ahenkli kılmaktadır (Erkal ve Ark.1998).

Sosyal Beceri kavramı "Social Skills" karşılığıdır ve İngilizce aslı çoğuldur (Bacanlı 1999).Sosyal becerinin literatürde pek çok tanımı yapılmıştır. Bunlardan bazıları şunlardır: Hops'a göre (1983) sosyal beceri, sosyal durumda sergilenen davranış biçimidir. Marlowe (1986)' göre sosyal beceri kişilerarası durumlarda, kişinin kendisi dâhil insanların duygu, düşünce ve davranıșlarını anlama ve anlayıșa uygun davranma yeteneği olarak tanımlamaktadır (Marlowe 1986).Sorias (1986) sosyal beceriyi; bireyin çevresi ile olumlu ilişkiler kurması, gerektiğinde diğer insanlardan yardım isteyebilmesi ve kendisine ters gelen istekleri geri çevirebilmesini kolaylaştıran öğrenilmiş davranışlar olarak tanımlamıştır(Sorias 1986). Bacanlı(2001) sosyal beceriyi, bireyin diğer insanlarla başarılı bir şekilde etkileşiminde bulunmasını sağlayan davranışlar olarak tanımlamaktadır(Bacanlı 2001). 
Yukarıdaki tanımlarda sosyal beceriler, öğrenilmiş davranışlar olarak ele alınmaktadır. Carledge ve Milburn(1983), sosyal beceri tanımlarının çoğundaki ortak noktaları şu şekilde belirlemektedir.

1- Başkalarında olumlu tepkiler getirecek ve olumsuz tepkilerin gelmesini engelleyecek, başkalarıyla etkileşimi mümkün kılacak, sosyal olarak kabul edilebilir olan öğrenilmiş davranışlar olarak sosyal beceriler,

2- Çevrede etki burakan, hedefe yönelik davranışlar olarak sosyal beceriler,

3- Duruma özgü ve sosyal beceriye göre değișen sosyal beceriler,

4- Hem belirli gözlenebilir davranışlar, hem de gözlenemeyen bilişsel ve duyuşsal öğeler içeren davranışlar olarak sosyal becerilerdir(Yüksek 1997).

Bahsedilen tanımlara bağlı olarak sosyal becerileri oluşturan çeşitli yapılar oluşturulmuştur. Bunlardan Riggio (1986;1989) tarafindan ortaya atılan yapı bilim dünyasında en çok kabul görenlerden birisidir. Riggio $(1986 ; 1989)$ sosyal becerileri oluşturan altı yap1 olduğunu belirtmektedir. Riggio'nun geliştirmiş olduğu Sosyal Beceri Envanteri'nde (Social Skills Inventory) sosyal beceri ve sosyal becerileri oluşturan yapılar aşağıdaki gibi ele alınmaktadır:

1. Duyuşsal anlatımcılık (emotional expressivity): Bireylerin sözel olmayan iletişim becerilerini, özellikle duyuşsal mesajları gönderme becerilerini ifade etmektedir.

2. Duyuşsal duyarlık (emotional sensitivity): Diğerlerinin sözel olmayan mesajlarını alma ve anlamlandırma becerisi ifade eder.

3. Duyuşsal kontrol (emotional control): Bireylerin duyuşsal ve sözel olmayan tepkilerini düzenleme ve kontrol becerileriyle ilgilidir.

4. Sosyal anlatımcılık (social expressivity): Bireylerin birbirleriyle sosyal iletişim kurma ve iletişime katılma becerilerini ifade etmektedir.

5. Sosyal duyarlık (social sensitivity): Diğerlerinin sözel iletişimlerini alma, anlama ve yorumlama becerilerini içermektedir.

6. Sosyal kontrol (social control): Sosyal rol oynama ve bireyin sosyal olarak kendini ortaya koyma becerilerini ifade eder.

Sporun çoğunlukla kolektif bir etkinlik olduğu göz önünde bulundurulduğunda, sportif faaliyetler arac1lığı ile sporla ilgilenen bireyler değişik insan grupları ile sosyal ilişkiye girmektedirler. Spor, bireyin kendi dar dünyasından kurtularak başka ortamlarda, başka kişilerden inançlardan düşüncelerden insanlar ile diyalog içerisinde bulunmasını, onlardan etkilenmesini ve onları etkilesini sağlamaktadır. Bu yönü ile sporun, yeni dostlukların kurulmasına, pekiştirilmesine ve sosyal kaynaşmaya destek sağladığı söylenebilinir (Çamlıyer, Çamliyer 2001).

Üniversitelerin Beden Eğitimi ve Spor Yüksekokulunda okuyan öğrencilerin de eğitimlerini tamamladıktan sonra sporun içerisinde olmaları münasebetiyle, kişilerle ilişki halinde olmaları dolayısıyla sosyal beceri düzeylerinin yüksek olması gerektiği yadsınamaz bir gerçektir.

\section{MATERYAL VE YÖNTEM}

Araştırmada mevcut durumu ortaya çıkarmayı amaçlayan betimsel tarama ve ilişkisel taramaya yönelik bir yöntem kullanılmıştır. Araştırmanın evrenini 2015-2016 eğitim öğretim yılında, bahar döneminde Karamanoğlu Mehmetbey Üniversitesi, Beden Eğitimi ve Spor Yüksekokulunda 466 (162 kadın ve 304 erkek) öğrenci oluşturmaktadır. Araştırmanın örneklemi ise evreni oluşturan tüm öğrencilere anket verilmiş ancak 208 anket değerlendirmeye alınmıştır.

Araştırmada Riggio(1986) tarafindan geliştirilen 1989 yılında revize edilerek bugünkü şeklini alan Yüksek(1997) tarafindan Türkçeye uyarlanan "Sosyal Beceri (Kendini Tanımlama) Envanteri kullanılmıştır. Sosyal Beceri Envanterinin tamamı 90 maddeden ve her bir alt ölçek 15 maddeden oluşmaktadır. Sosyal Beceri Envanterinin Alt Ölçekleri; Duyuşsal Anlatımcılık, Duyuşsal Duyarlılık, Duyuşsal Kontrol, Sosyal Anlatımcılık, Sosyal Duyarlılık ve Sosyal kontrol'den oluşmaktadır. Beşli likert tipi olan bu envanterin değerlendirilmesi ise; "Hiç Benim Gibi Değil" 1, "Biraz Benim Gibi" 2, "Benim Gibi" 3, "Oldukça Benim Gibi" 4, ve "Tamamen Benim Gibi" 5 puan olarak hesaplanmaktadır. Envanterdeki bazı soruların puanları ise tersine çevrilerek hesaplanmaktadır. Cevap anahtarlarında, en düşük puan 1, en yüksek puan ise 5'tir. Sosyal Beceri Envanterinin bütününden en düşük 90 , en yüksek 450 puan alınabilmektedir (Yüksek1997). İstatistiksel değerlendirmeler SPSS for Windows version 15,00 paket programı kullanılarak analizi yapılmıştır.

Araştırmaya katılan öğrencilerin demografik özellikleri şu şekilde yorumlanmıştır. Öğrencilerin 80 (\% 38,4)'ni kadın 128 (\% 61,6 )'i ise erkektir. Öğrencilerin yaşlara göre dağılımları ise; 60 ( \% 28,8 )’1 18-20 yaş arası, $120(\%$ 57,7)'si 21-23 yaş arası ve $28(\% 13,5)$ 'i ise 24 yaş ve üzeri şeklindedir. Öğrencilerin Okudukları Bölümlere göre dağılımları ise; 101 (\% 48,5)'i Beden eğitimi ve Spor Öğretmenliği Bölümünde, $45(\% 21,6)$ 'i Spor Yöneticiliği I.Ögretim ve $62(\% \quad 29,9)$ 'si ise Spor Yöneticiliği II. Öğretimde okumaktadır. Öğrencilerin okudukları sınıflara göre dağılımları ise; 70 (\% 33,6)'i birinci sinıfta, $54(\%$ $25,9)$ 'ü ikinci sinıfta, 62 (\% 29,8)'si üçüncü sinıfta ve 22 (\% $10,7)$ 'si ise dördüncü sinıfta okumaktadır. Öğrencilerin kaldıkları yerlere göre dağılımları ise; 117 (\% 56,2)'i öğrenci evinde, 35 (\% 16,8)'i Devlet Yurdunda, 33 (\% 15,9)'Ü özel yurtta ve $23(\% 11,1)$ '̈u ise ailesiyle beraber kalmaktadırlar. Öğrencilerin 117 (\% 56,2)'i öğrenim kredisi almakta, 91 (\% $43,8)$ 'i ise öğrenim kredisi almamaktadır. Öğrencilerin aylık gelir durumlarına göre dağılımları ise; $13(\% 6,2)$ 'ü 0 - 250 TL aras1, 97 (\% 46,6)'i 251-500 TL aras1, 48 (\% 23,1)'i 501750 TL arası ve 50 (\% 24,1)'si ise $751 \mathrm{TL}$ ve yukarıs1 şeklindedir. Öğrencilerin annelerinin eğitim durumlarına göre dağılımları ise; 46 (\% 22,1)'1 okuryazar değil, 99 (\% 47,6)’u ilkokul, 35 (\% 16,8)'i ortaokul ve $28(\% 13,5)^{\prime}$ i ise lise mezunudur. Öğrencilerin babalarının eğitim durumlarına göre dağılımları ise; 94 (\% 45,2)'ü ilkokul, 47 (\% 22,6)'si ortaokul ve $67(\% 32,2)$ 'si ise lise mezunudur. Öğrencilerin kendileri dâhil kardeş sayılarına göre dağılımları ise; 35 (\% 16,8)'i iki, 68 (\% 32,7)'i üç, 46 (\% 22,1)'s1 dört, 18 (\% 8,6)'i beş, 14 (\% $6,7)$ 'ü altı ve 27 (\% 13,1)'si ise 7 ve üzeri olarak tespit edilmiştir. Öğrencilerin babalarının meslek gruplarına göre dağılımları ise; 60 (\% 28,8)'1 emekli, 17 (\% 8,2)'si memur, 
34 (\% 16,3)'ü işçi, 19 (\% 9,2)'u esnaf, 36 (\% 17,3)'sı çiftçi ve $42(\% 20,2)$ 'si ise serbest meslek şeklindedir. Öğrencilerin $21(\%$ 10,0)'inin annesi bir işte çalışırken, 187 (\% 90,0)'sinin ise annesi bir işte çalışmamaktadır. Öğrencilerin spora ilgi düzeylerine göre dağılımları ise; 51 (\% 24,5)'i ulusal düzeyde müsabakalara katılmış, 19 (\% 9,2)'u uluslar arası düzeyde müsabakaya katılmış, $122(\% 58,6)$ 'si yarışmalara katılmadan spor yapmış ve $16(\% 7,7)$ 'sı ise seyirci ve taraftar olarak sporla ilgilenmişlerdir. Öğrencilerin yaşamlarının büyük bir bölümünü geçirdiği yerleşim merkezine göre dağıllımları ise; 98 (\% 47,1)'i il merkezinde, 73 (\% 35,1)'ü ilçe merkezinde, $12(\% 5,7)$ 'si kasaba ve 25 (\% 12,1)'si ise köy şeklindedir.

\section{BULGULAR}

Çizelge 1: Katılımcıların Genel Olarak Sosyal Becerilerinin Alt Boyutlarıyla Toplam Puanına ilişkin Sonuçları

\begin{tabular}{|c|c|c|c|c|c|c|}
\hline Sosyal Beceri Alt Boyutları & $\mathrm{n}$ & $\bar{X}$ & Ss & Min. & Max & $\begin{array}{l}\text { Envanterden Alınabilecek } \\
\text { En Düşük ve En Yüksek } \\
\text { Puan }\end{array}$ \\
\hline Duyuşsal Anlatımcılık & 208 & 44,9087 & 6,01900 & 28,00 & 65,00 & $15-75$ \\
\hline Duyuşsal Duyarlılık & 208 & 51,2788 & 8,28765 & 30,00 & 71,00 & $15-75$ \\
\hline Duyuşsal Kontrol & 208 & 44,5721 & 6,52565 & 25,00 & 67,00 & $15-75$ \\
\hline Sosyal Anlatımcılık & 208 & 48,5240 & 8,18443 & 27,00 & 73,00 & $15-75$ \\
\hline Sosyal Duyarlılık & 208 & 47,3990 & 8,20624 & 30,00 & 69,00 & $15-75$ \\
\hline Sosyal Kontrol & 208 & 50,4375 & 7,81031 & 35,00 & 71,00 & $15-75$ \\
\hline Toplam Puan & 208 & 287,1202 & 25,32189 & 237,00 & 358,00 & $90-450$ \\
\hline
\end{tabular}

Çizelge 1'de araştırmaya katılan öğrencilerin geneline ait, sosyal beceri alt boyutları ve sosyal beceri toplam puan ortalamaları incelenmiştir. $\mathrm{Bu}$ inceleme sonucunda; öğrencilerin duyuşsal anlatımcılık alt boyutlarında $\bar{X}$ $=44,90$, duyuşsal duyarlılık alt boyutlarında $\bar{X}=51,27$, duyuşsal kontrol alt boyutlarında $\bar{X}=44,57$, sosyal anlatımcilık alt boyutlarında $\bar{X}=48,52$, sosyal duyarlilik alt boyutlarında $\bar{X}=47,39$, sosyal kontrol alt boyutlarinda $\bar{X}=50,43$, sosyal beceri toplam puanında ise $\bar{X}=287,12$ puan ortalamasına sahip oldukları görülmektedir.
Araştırma kapsamına alınan öğrencilerin Sosyal Beceri Envanteri toplam puanından almış oldukları $\bar{X}=287,12$ puan ortalamas1, envanterin toplam puanından alınabilecek (Min. 90- Max 450) değerler göz önüne alındığında öğrencilerin orta seviyede sosyal beceri düzeylerine sahip oldukları söylenebilinir. Sosyal Beceri Envanterinin alt boyutlarından alınabilecek puan (Min. 15- Max. 75) göz öüne alındığında ise, öğrencilerin alt boyutlardan almış oldukları puan ortalamalar1 $\bar{X}=44,57 \quad-\quad \bar{X}=51,27$ arasında değiştiği için tüm alt boyutlarda da orta seviyede bir sosyal beceriye sahip oldukları ileri sürülebilir. 
S.Akpınar, Ö. Akpınar, K. Nas, V. Temel ve S. Ş. Birol / KMÜ Sosyal ve Ekonomik Araştırmalar Dergisi 17 (28): 80-84, 2015

Çizelge 2: Katılımcıların Kendileri Dahil Kardeş Sayıları Dağılımlarına Göre Sosyal Beceri Envanteri Alt Boyutları ve Toplam Puana İlişkin F-testi Sonuçları

\begin{tabular}{|c|c|c|c|c|c|c|c|}
\hline $\begin{array}{l}\text { Sosyal Beceri Alt } \\
\text { Boyutları }\end{array}$ & Kardeş Sayıs1 & $\mathrm{n}$ & X & Ss & $\mathrm{Sd}$ & $\mathrm{F}$ & P-Değeri \\
\hline \multirow{6}{*}{$\begin{array}{l}\text { Duyuşsal } \\
\text { Anlatımcılık }\end{array}$} & 2 & 35 & 46,4857 & 6,00182 & 202 & \multirow{6}{*}{2,336} & \multirow{6}{*}{,043 } \\
\hline & 3 & 68 & 44,7353 & 6,53719 & & & \\
\hline & 4 & 46 & 45,8696 & 4,91532 & & & \\
\hline & 5 & 18 & 45,7778 & 6,64703 & & & \\
\hline & 6 & 14 & 42,8571 & 5,31843 & & & \\
\hline & 7 ve Üzeri & 27 & 42,1481 & 5,53106 & & & \\
\hline \multirow{6}{*}{$\begin{array}{l}\text { Duyuşsal } \\
\text { Duyarlılık }\end{array}$} & 2 & 35 & 53,6286 & 9,02313 & 202 & \multirow{6}{*}{3,126} & \multirow{6}{*}{,010 } \\
\hline & 3 & 68 & 51,9265 & 7,61247 & & & \\
\hline & 4 & 46 & 50,4348 & 7,90401 & & & \\
\hline & 5 & 18 & 54,7222 & 8,16597 & & & \\
\hline & 6 & 14 & 47,0000 & 9,49494 & & & \\
\hline & 7 ve Üzeri & 27 & 47,9630 & 7,41351 & & & \\
\hline \multirow{6}{*}{$\begin{array}{l}\text { Duyuşsal } \\
\text { Kontrol }\end{array}$} & 2 & 35 & 44,3143 & 5,68161 & 202 & \multirow{6}{*}{,874 } & \multirow{6}{*}{, 500} \\
\hline & 3 & 68 & 43,4559 & 7,70236 & & & \\
\hline & 4 & 46 & 45,3913 & 5,59157 & & & \\
\hline & 5 & 18 & 45,2778 & 6,77196 & & & \\
\hline & 6 & 14 & 44,2143 & 5,75364 & & & \\
\hline & 7 ve Üzeri & 27 & 46,0370 & 6,00949 & & & \\
\hline \multirow{6}{*}{$\begin{array}{l}\text { Sosyal } \\
\text { Anlatımcilık }\end{array}$} & 2 & 35 & 48,5714 & 8,24366 & 202 & \multirow{6}{*}{5,092} & \multirow{6}{*}{, 000} \\
\hline & 3 & 68 & 48,7206 & 7,72831 & & & \\
\hline & 4 & 46 & 49,3696 & 8,23099 & & & \\
\hline & 5 & 18 & 55,1111 & 8,03587 & & & \\
\hline & 6 & 14 & 45,0000 & 5,72444 & & & \\
\hline & 7 ve Üzeri & 27 & 43,9630 & 7,41351 & & & \\
\hline \multirow{6}{*}{$\begin{array}{l}\text { Sosyal } \\
\text { Duyarlilik }\end{array}$} & 2 & 35 & 47,2857 & 8,80031 & 202 & \multirow{6}{*}{,648 } & \multirow{6}{*}{,663 } \\
\hline & 3 & 68 & 48,5000 & 9,11043 & & & \\
\hline & 4 & 46 & 46,7391 & 7,34978 & & & \\
\hline & 5 & 18 & 48,4444 & 8,14011 & & & \\
\hline & 6 & 14 & 45,2143 & 7,15949 & & & \\
\hline & 7 ve Üzeri & 27 & 46,3333 & 7,07651 & & & \\
\hline \multirow{6}{*}{$\begin{array}{l}\text { Sosyal } \\
\text { Kontrol }\end{array}$} & 2 & 35 & 49,6857 & 8,18453 & 202 & \multirow{6}{*}{,304 } & \multirow{6}{*}{,910 } \\
\hline & 3 & 68 & 51,0147 & 7,69860 & & & \\
\hline & 4 & 46 & 50,0000 & 7,65942 & & & \\
\hline & 5 & 18 & 51,8333 & 10,91276 & & & \\
\hline & 6 & 14 & 50,0000 & 5,02302 & & & \\
\hline & 7 ve Üzeri & 27 & $\begin{array}{l}50,0000 \\
\end{array}$ & 7,04928 & & & \\
\hline \multirow{6}{*}{$\begin{array}{l}\text { Toplam } \\
\text { Puan }\end{array}$} & 2 & 35 & 289,9714 & 26,99835 & 202 & \multirow{6}{*}{3,060} & \multirow{6}{*}{, 011} \\
\hline & 3 & 68 & 288,3529 & 25,63042 & & & \\
\hline & 4 & 46 & 287,8043 & 25,36631 & & & \\
\hline & 5 & 18 & 301,1667 & 26,31987 & & & \\
\hline & 6 & 14 & 274,2857 & 18,94701 & & & \\
\hline & 7 ve Üzeri & 27 & 276,4444 & 18,79921 & & & \\
\hline
\end{tabular}

Çizelge 2'de katılımcıların sosyal beceri alt boyutları ve toplamına ait puan ortalamalarının kendileri dahil kardeş sayıları değişkenine göre farklılaşıp farklılaşmadığ $1 \mathrm{f}$ testi ile incelenmiştir. Buna göre sosyal beceri alt boyutlarında duyuşsal anlatımcilık, duyuşsal duyarlılık, sosyal anlatımcilık ve toplam puan ortalamalarında sosyal becerilerinde anlamlı bir ilişki bulunmuştur. Kardeş sayısı az olanların sosyal beceri puanları kardeş sayısı fazla olanlara oranla daha yüksek olduğu tespit edilmiştir.

Araştırmaya katılan öğrencilerin okudukları sınıf değişkenine göre sosyal beceri düzeylerinde sadece duyuşsal kontrol alt boyutunda anlamlı bir ilişki bulunmuştur. Buna göre 1. Sinıfta okuyan öğrencilerin sosyal kontrol alt boyutunda diğer sinıflarda okuyan öğrencilerden daha yüksek olduğu tespit edilmiştir.

Araştırmaya katılan öğrencilerin Annelerinin eğitim durumlarında sosyal beceri envanterinin alt boyutlarından sadece duyuşsal anlatımcılık alt boyutunda anlamlı bir iliş̧ki bulunmuş olup, burada da öğrencilerin annelerinin eğitim seviyesi yüksek olanların duyuşsal anlatımcılık puanlarının da yüksek olduğu tespit edilmiş̧ir. Aynı olay öğrencilerin babalarının eğitim durumlarında da mevcuttur. Öğrencilerin babalarının eğitim durumu yüksek olanların sosyal beceri alt boyutlarından duyuşsal anlatımcılık puanlarının yüksek olduğu bulunmuştur.

Araştırmaya katılan öğrencilerin yaşamlarının büyük bir kısmının geçirdikleri yer değişkenine göre de sosyal beceri alt boyutlarından duyuşsal anlatımcılık, duyuşsal kontrol ve sosyal kontrol alt boyutlarında da anlaml bir ilişki bulunmuştur. Buna göre il merkezinde yaşayanların sosyal beceri alt boyutlarından duyuşsal anlatımcılık, duyuşsal kontrol ve sosyal kontrol puan ortalamaları daha yüksek olduğu söylenebilinir.

Öğrencilerin cinsiyet, yaş, okuduğu bölüm, kaldığı yer, kredi alıp almama, aylık gelir durumu, babalarının mesleği, annelerinin çalışıp çalışmamaları ve spora ilgi 
düzeyleri değişkenlerine göre ise de istatistiksel olarak

\section{TARTIŞMA VE SONUÇ}

$\mathrm{Bu}$ araştırma Beden Eğitimi ve Spor Yüksek Okulunda okuyan öğrencilerin sosyal beceri düzeylerini inceleyerek, demografik özelliklerine göre farklılaşıp farklılaşmadığını ortaya koymak amacıyla yapılmıştır. Araştırmaya katılan öğrencilerin Sosyal beceri envanterinden almış oldukları puan ortalamaları $\bar{X}$ $=287,12$ olmaları münasebetiyle envanterden alınabilecek (Min. 90- Max 450) değerler göz önüne alındığında öğrencilerin orta seviyede sosyal beceri düzeylerine sahip oldukları söylenebilinir. Yapılan bu çalışmada öğrencilerin cinsiyet, yaş, okuduğu bölüm, kaldığı yer, kredi alıp almama, aylık gelir durumu, babalarının mesleği, annelerinin çalışıp çalışmamaları ve spora ilgi düzeyleri değişkenlerine göre istatistiksel olarak anlamlı bir fark bulunamazken, okuduğu sınıf, annelerinin eğitim durumu, babalarının eğitim durumu, kardeş sayıları ve yaşamlarının büyük bir bölümünü geçirdikleri yerleşim merkezi değişkenlerine göre ise de istatistiksel olarak anlamlı bir fark bulunmuştur.

Çetin ve Kuru(2009) tarafından, İç Anadolu bölgesinde bulunan 11 üniversitenin Beden Eğitimi ve Spor Yüksekokulu öğrencilerinin sosyal beceri düzeylerini tespit etmek amacıyla yapılan çalışmalarında, öğrencilerin $X=285,10$ puana, dolayısiyla orta seviyede sosyal beceri düzeylerine sahip oldukları tespit etmişlerdir. Demografik özelliklere göre de, cinsiyet (kadınların daha yüksek sosyal beceriye sahip oldukları), okudukları sinıf (1. Sinıfta okuyan öğrencilerin daha yüksek sosyal beceriye sahip oldukları) ve yaptıkları spor branşı (elit düzeyde spor yapanların daha yüksek sosyal beceriye sahip oldukları) sosyal beceri düzeylerinin farklılaştığını tespit etmiştir. Bu çalışma bizim yapmış olduğumuz çalışmayla paralellik arz etmektedir. Çalışmamızın evrenini oluşturan Karamanoğlu Mehmet Bey Üniversitesi ülkemizin iç Anadolu bölgesinde yer almaktadır.

Avşar ve Kuter(2007) tarafindan "Beden Eğitimi ve Spor Bölümü Öğrencilerinin Sosyal Beceri Düzeylerinin belirlenmesi" amacıyla yapılan çalışmada ise, öğrencilerin $X=292,60$ puana dolayısıyla orta seviyede sosyal beceri düzeylerine sahip oldukları tespit etmişlerdir. Demografik özelliklere göre de Cinsiyet (kadınların daha yüksek sosyal beceriye sahip oldukları),kardeş sayısı (kardeş sayısı az olanların daha yüksek sosyal beceriye sahip oldukları), sosyo ekonomik durumu ( Sosyo ekonomik durumu düşük olanların daha yüksek sosyal beceriye sahip oldukları) ve mezun oldukları lise (Anadolu lisesi mezunlarının daha yüksek sosyal beceriye sahip oldukları) sosyal beceri düzeylerinin farklılaştığını tespit etmişlerdir.

Akpınar ve arkadaşları(2012) tarafindan "Aday Beden Eğitimi Öğretmenlerinin Sosyal Beceri Düzeylerinin Belirlenmesi" amacıyla yapılan çalışmada öğretmen adaylarının $X=285,45$ puana dolayısıyla orta seviyede sosyal beceri düzeylerine sahip oldukları tespit etmişlerdir. Demografik özelliklere göre de, aylık gelir durumu (Aylık gelir durumu yüksek olan öğrencilerin daha yüksek sosyal beceriye sahip oldukları), yaş (21-23 yaş arası olan öğrencilerin daha yüksek daha yüksek sosyal beceriye anlamlı bir fark bulunamamıştır.

sahip oldukları),okudukları sınıf (son sınıf öğrencilerinin daha yüksek sosyal beceriye sahip oldukları) ve annelerinin eğitim durumu (eğitim durumu yüksek olanların daha yüksek sosyal beceriye sahip oldukları), sosyal beceri düzeylerinin farklılaştığı tespit etmişlerdir.

\section{KAYNAKLAR}

Akpınar S., Temel V., Nas K,(2012). An exploration of candidate teachers' social skills levels:Age, gender and other differences"", Prime Journal of business administration and management, 338-343 pp., ( Indexed by: International Society of Universal Research - Eyesource

Avşar Z., Kuter F.Ö (2007). Beden Eğitimi ve Spor Bölümü Öğrencilerinin Sosyal Sosyal Beceri Düzeylerinin Belirlenmesi(Uludağ Üniversitesi Örneği). Çanakkale 18 Mart Üniversitesi, Journal of Theory and Practice in Education.3 (2) 197-206.

Bacanlı H(1999). Sosyal Beceri Eğitimi, İlköğretimde Rehberlik Nobel Yayınevi. Ankara

Bacanlı H(2001). Sosyal Beceri Eğitimi. Nobel yayın Dağıtım. Ankara.

Çamliyer H., Çamliyer H(2001). Eğitim Bütünlüğü içerisinde Çocuk Hareket Eğitimi ve Oyun Emek Matbaacilık, Manisa.

Çetin M.Ç, Kuru E(2009). Beden Eğitimi ve Spor Bölümü Öğrencilerinin Sosyal Beceri Düzeylerinin Belirlenmesi Selçuk Üniversitesi, Beden Eğitimi ve Spor Bilim Dergisi. 11 (1) 1-8.

Erkal M., Güven O., Ayan D(1998). Sosyolojik Açıdan Spor. Der Yayınları. İstanbul.

Gode O., Alkan V(1998). Denizli Orta Öğretim Kurumlarındaki Sporcu öğrencilerin Derslerindeki ve Spor Yaşantılarındaki Başarılarının Karşılaştırılması. Pamukkale Üniversitesi, Eğitim Fakültesi Dergisi 4(1) s.14-21.

Hops H. (1983), Children's social competence and skill: Current research pratices and future directions. Behavior Therapy, 14, 3-18.

Marlowe H.A(1986). Social Intelligence Evidence For Multidimensionality andConstruct Indepence. Journal of Educational Psyclogy. 78(1)s:52-58.

Riggio, R.E. (1986). Assessment of Basic Social Skills. Journal of Personality and Social Psychology, 51 (3), 649-660.

Riggio, R. E. (1989). Social Skills Inventory. Consulting Psychologists Press, Inc

Sorias O(1986). Sosyal Beceri ve Değerlendirme Yöntemleri Psikoloji Dergisi 5(1) s:42-45.

Yüksek G(1997). Sosyal Beceri Eğitiminin Üniversite Öğrencilerinin sosyal Beceri Düzeyine Etkisi. Gazi Üniversitesi. Yayınlanmamış Doktora Tezi. Ankara. 